
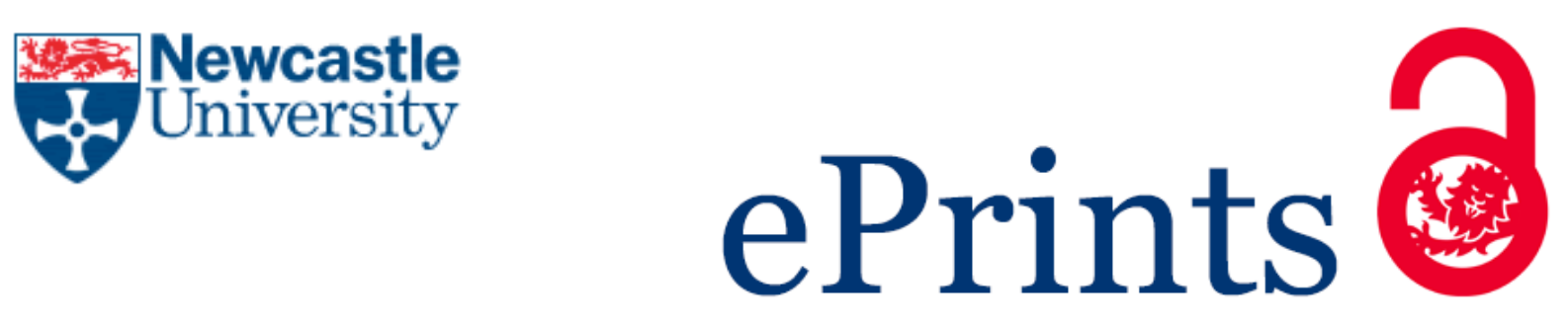

Calatayud MA, Mangan J, Palacin R.

Vulnerability of international freight flows to shipping network disruptions: A multiplex network perspective.

Transportation Research Part E: Logistics and Transport Review 2017, 108, 195-208

Copyright:

(c) 2017. This manuscript version is made available under the CC-BY-NC-ND 4.0 license

DOI link to article:

https://doi.org/10.1016/j.tre.2017.10.015

Date deposited:

$01 / 11 / 2017$

Embargo release date:

01 November 2018

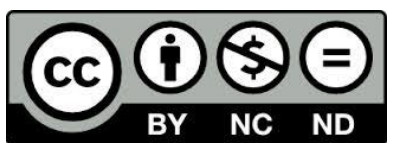

This work is licensed under a

Creative Commons Attribution-NonCommercial-NoDerivatives 4.0 International licence 


\title{
Vulnerability of international freight flows to shipping network disruptions: a multiplex network perspective
}

\begin{abstract}
As freight flows through global supply chains intensify, dependence upon maritime transportation increases. This paper explores the risks that international freight flows are exposed to as a function of the multiple complex structure of liner shipping networks. Based on network modelling of over 80 networks and simulation of attacks to seven strategic nodes in the Americas, the paper shows that the vulnerability of international freight flows to disruptions in maritime transportation services varies according to the country of origin of such flows and the role that the country plays in the multi-layered maritime transportation network.
\end{abstract}

Keywords: maritime transportation, logistics, complex networks, vulnerability, international trade.

\section{Introduction}

During the second half of the twentieth century, international trade in goods grew twice as fast as world output, driven by globalisation, trade liberalisation, delocalisation of production activities, vertical integration, lower transportation costs and the use of information technologies in international business and production (Blonigen and Wilson, 2013). Supply chains became more international and complex, encompassing numerous actors, processes, products and locations (Myers et al., 2006; Creazza et al., 2010; Wagner and Neshat, 2010; Christopher and Holweg, 2011). In this context, a variety of risks threatens to disrupt the smooth flow of international materials and final products along supply chains, with severe potential consequences for international business (Bogataj and Bogataj, 2007; Tang and Musa, 2011). Each day that a product is delayed reduces the possibility of it being traded by $1 \%$ ( $6 \%$ when products are time-sensitive) (Djankov et al, 2010) and reduces its value by $0.8 \%$ (Hummels and Schaur, 2013).

Among the main risks global supply chains face are disruptions in the flow of goods transported internationally. Lack of adequate infrastructure and transport services, failure of critical infrastructure, adverse weather conditions, cumbersome customs processes, and labor conflicts, among others, can increase logistics costs and raise uncertainty in already complex environments. As a result, the efficiency of the international transport chain has become critical for supply risk management and performance. Among transport modes, the literature in this regard has paid particular attention to the international shipping mode. Indeed, maritime transportation is the dominant mode of transport in international trade, with around $80 \%$ of global trade by volume and over $70 \%$ of global trade by value carried by sea and handled by ports worldwide (UNCTAD, 2015). These large shares suggest that ports (as nodes) and shipping services (as links) play an important role in many global supply chains (Notteboom and Rodrigue, 2005; Mangan et al., 2008; Panayides and Song, 2008). Because of this, a large body of 
literature advocates for port-supply chain integration, suggesting that sharing information between a port and other supply chain actors contributes to reduced order cycle times, a cut in inventories and more flexible systems (Panayides and Song, 2013; Woo et al., 2013).

Despite this increasing attention and the relevance of maritime transportation for global supply chains, the extent to which the configuration of liner shipping networks may affect the international flow of materials and final products remains largely unexplored. Literature in the areas of Transport Geography and Transport Economics that analysed the characteristics of transport networks showed that the structure of shipping routes does not entirely overlap trade patterns (Ducruet and Notteboom, 2012; Calatayud et al., 2017). In this context, the research question investigated in this paper can thus be summarised as 'to what extent does the specific configuration of shipping networks create risks for international freight flows. Indeed, the strategies of shipping lines and the different positions that ports and countries may have in the maritime network can play an important role in smoothing or hampering international freight flows across global supply chains. The contribution of this paper to the literature is twofold: (1) it uncovers the structure of liner shipping networks and the risks they may pose to international freight flows, and (2) it does so by applying multiple complex network analysis, a technique that scholars recently started applying to air transportation, but that still remains largely underused in maritime transportation. The results of this paper may be useful not only for researchers, but also for practitioners in both private and public sectors. Having a better understanding on the risks that the structure of liner shipping networks may pose to international trade flows may help design more efficient risk management strategies for international freight flows, as well as provide input for transportation, trade and infrastructure investment strategies in the public sector.

The paper is organised as follows: Section 2 presents the literature review; Section 3 presents the methodology; Section 4 presents the results and discusses the implications for academic research and policy-making; and Section 5 presents the conclusions of this research.

\section{Literature review}

Risks can be defined as the combination of the probability of occurrence of an event and its negative consequences (Holton, 2004). In the context of international freight, this could mean any risk that prevents goods with origin in a given country from reaching their destination markets. With the accelerated growth of international trade and the emergence of global supply chains, dependency on transportation has increased (Tang and Musa, 2011). Among transportation modes, shipping has emerged as the backbone of globalisation and international trade (Creazza et al., 2010). While the development of containerization has certainly allowed countries and firms to improve efficiency and reliability in their international trading links, it has exposed them to a new type of risk: disruptions in maritime transport networks (Acciaro and Serra, 2013). Adverse weather conditions, natural disasters, terrorist attacks, regulatory barriers, and changes in shipping companies' strategies are among the main 
factors that can create disruptions in maritime transportation (Ducruet et al., 2010; Earnest et al., 2012). For example, the decision following the 2011 Fukushima Daiichi disaster to close the ports of Yokohama and Tokyo led Japanese exports, and particularly its auto parts supply chains to a halt that cost Toyota alone an estimated US\$73 million per day with knock-on effects to automobile manufacturers around the world (Earnest et al., 2012). More recently, the filing for bankruptcy of Hanjin shipping line - the world's seventh-largest container line - in August 2016 created confusion in ports and firms around the world. Millions of dollars' worth of merchandise sat on vessels seized on behalf of creditors, denied entry to ports or left unable to dock, while firms tried to make alternative arrangements to meet contractual obligations with their clients and minimise the financial impact of supply chain disruptions (The Guardian, 2016).

Given the importance of maritime transportation for the smooth flow of international trade and the efficient performance of global supply chains, the structure of shipping transportation business and the strategies adopted by liner shipping companies have drawn the attention of both supply chain and transportation researchers (Lam and Yap, 2011). According to the literature that explored the determinants of port choice for liner shipping services, port choice is a function of the overall network cost and performance (Mangan et al., 2001; Ducruet and Notteboom, 2012). Shipping lines face a tradeoff between the requirements of the customers, who demand direct services between ports of origin and destination of their products, and operational cost considerations leading shipping companies to optimise ship utilisation and take advantage of scale economies in vessel size (Feng et al., 2012). Balancing the trade-off between supply and demand, shipping companies design their service routes in terms of: (i) the liner service type, (ii) the number and order of port calls in combination with the actual port selection process, (iii) vessel speed, (iv) frequency and (v) vessel size and fleet mix (Notteboom, 2006; Christiansen et al., 2013).

With the aim of improving efficiency and profitability, many shipping companies have adopted the strategy of hub-and-spoke networks, where the lowest cost for the entire network is achieved by routing via hubs, the use of different types of vessels in the network for optimal ship utilisation, and the amalgamation of flows to benefit from scale economies in maritime transportation (Fremont and Soppe, 2004; Fremont, 2007; Imai et al., 2009; Gelareh et al., 2010; Meng and Wang, 2011; Moon et al., 2015). The hub-and-spoke configuration has created a hierarchy among ports, with shipping companies having different functions in the network. Among these are ports dedicated to transhipment and/or relay/interlining, located in strategic geographic positions, which multiply shipping options and improve connectivity within the network through their pivotal role in regional hub-and-spoke networks (Ducruet and Notteboom, 2012; Ducruet, 2017).

Research on the structure of maritime networks and liner shipping strategies has benefited from the adoption of network analysis where, with the assistance of advanced analytical software, maritime connections are abstracted into graphs made of nodes and links. Elements of graph theory are used to uncover the properties and laws governing maritime networks, as well as their internal efficiencies and vulnerabilities (Ducruet and Lugo, 2011), improving available knowledge in the field obtained using other methods like gravity models (Kaluza et al., 2010) or variables such as total traffic volume (Xu et al., 
2015). Indeed, studies applying network analysis showed that the container shipping network shared the characteristics of other networks found in nature and sciences: (i) it was a scale-free network, where a limited number of nodes were highly connected and links among nodes were distributed according to a power-law distribution (Barabasi and Albert, 1999); (ii) it was a 'small-world' network, with high cluster densities among nodes (Watts and Strogatz, 1998); and (iii) a giant component could be found in the network, to which almost all nodes belonged to. In addition, the particular configuration of maritime networks led scholars to suggest that they did not entirely overlap trade patterns but they followed the economic organisation of shipping lines (Hu and Zhu, 2009; Ducruet et al., 2010; Ducruet and Lugo, 2011; Ducruet and Noteboom, 2012; Ducruet and Zaidi, 2012; Ducruet, 2016a; Calatayud et al., 2017).

Network analysis has also been applied to study the vulnerability and resilience of maritime shipping networks. Lhomme (2016) assessed the vulnerability of the world maritime network to a single node breakdown as well as to the removal of a group of nodes. The author showed that even though the world maritime network was relatively resilient, it was quite vulnerable to the breakdown of the most important ports, particularly those located in Asia. He also showed that some European ports were more critical than expected. Ducruet (2016b) analysed the dependency of the world maritime network on the Panama and Suez canals, and estimated the effects of removing canal-dependent flows from the network. He concluded that while there was a decreasing importance of canal shipping in the context of growing south-south trade exchanges, certain areas remained more dependent on canal flows than others, such as Asia, Europe, and North America.

Recently, literature in the Transportation field has started using multiple complex networks (also referred to as multiplex networks), to deepen the understanding of networks structures (Cardillo et al., 2013). Studies applying multiplex networks aim at uncovering the multiple relations between nodes. Relations between nodes may be based on different criteria, each criterion represented as a layer in a multi-layer network. According to each criterion, nodes may take different positions within a network (De Domenico et al., 2015). In the field of air transportation, available studies showed that the air transport network was a multilayer network as the result of the aggregation of airline route networks (Lordan et al., 2014). Compared to a single layer network, such a structure strongly increased the resilience of the system - defined as the ability of a network to cope with a disruptive event (Sheffi, 2005; Cardillo et al., 2013) - and thus enhanced network connectivity. In the case of maritime transportation, Kaluza et al. (2010) suggested that the global shipping network was a multi-layered structure of three classes of cargo ships - container ships, bulk dry carriers and oil tankers - that spanned distinct subnetworks. In turn, Ducruet (2013 and 2017) analysed the different relationships and dynamics between ports according to five categories of vessels: solid bulk, liquid bulk, container, general cargo, and passenger/vehicles.

These results suggest that, although of relatively recent use, multiplex networks can provide interesting results to understand the complexity of transport systems. There is however no study available on the multiple layers of the maritime network based on the liner shipping companies' strategies. This research contributes addressing this gap via understanding the degree of dependency and vulnerability that 
international freight flows may face as a result of the specific characteristic of the multiplex network in maritime transportation.

\section{Methods}

The research question we posit for investigation is 'to what extent does the specific configuration of shipping networks create risks for international freight flows. To address this question, multiple complex network analysis is used to uncover and model the structure of liner shipping services. As evidenced in the literature, each shipping company designs its network seeking to minimise overall network costs and maximise network performance (Mangan et al., 2001; Ducruet and Notteboom, 2012). In particular Because of this, port choices and network configurations often differ among shipping lines. When nodes are connected according to different criteria - in this case, the different strategies adopted by shipping lines to design their route networks- multiplex networks better fit the real situation, catching the different dynamics developing in each layer of the multiple complex network (Cardillo et al., 2013; Kivela et al., 2014; Ducruet, 2017). Therefore, we apply multiplex network analysis to build the multiplex shipping network - that is, the network of maritime connections among ports that results from the sum of individual liner shipping companies' networks - and explore dependency and vulnerability for global supply chains emerging from structure of such multiplex shipping network.

Due to the predominance of containerisation and maritime transportation in international trade, the focus of this paper is on containerships and liner shipping services. Indeed, about $70 \%$ of world trade value is transported on containerships, making liner shipping the most important mode of maritime transportation (Windeck, 2012). One geographic region was selected for applying the approach proposed, the Americas (encompassing North, Central and South America, and the Caribbean), which includes 32 countries $^{[1]}$ and shows high intensity of intra-regional trade flows. Intra-regional trade in the Americas accounts for about $53 \%$ of the total value of the region's international trade flows.

Approximately $74 \%$ of the commodities traded intra-regionally are traded by sea. Thus, the maritime transport network is clearly one crucial aspect for intra-regional trade.

Given that the purpose of this paper is primarily to analyse the risks and vulnerability that international freight flows may face as a result of the specific structure of the multiplex shipping network, and not the trends and evolution of the network, data was collected for one point in time only. While analysing changes in the structure of multiplex shipping networks is beyond the scope of this paper, recent studies have evidenced the generally static and unchanging structure of such shipping networks at the macro (country and global) level (Ducruet, 2017). Following a detailed analysis on data availability and validity, the year 2011 was selected for the analysis. Within the period 2010-2014 (the last five years of available data), 2011 was selected as it was the most stable year in the Americas in terms of economic and weather factors, since there were neither trade shocks nor major natural disasters in the Americas in 2011 that affected trade and transport flows significantly within the region. 
In order to understand to what extent the multiplex shipping network creates risks international freight flows in the Americas, we first built and analysed the structure of the overall shipping network, including all shipping services. We labelled this network the Maritime Shipping Network or 'MSN'. Next, we analysed the network structure of the most important shipping lines in the Americas. Given that the MSN comprises the individual networks of liner shipping companies, and that countries are served in different ways by shipping lines, this step is important to understand the structure of those shipping lines and to what extent international freight flows between countries in the Americas depend on the different shipping lines. Finally, to understand how vulnerable the multiplex shipping network in the Americas may be to attacks to critical hubs, and how those attacks could affect international freight flows within the region, we simulated 'attacks' to the most important seven countries in the MSN. These steps are summarised in Figure 1 and further explained in the paragraphs below.

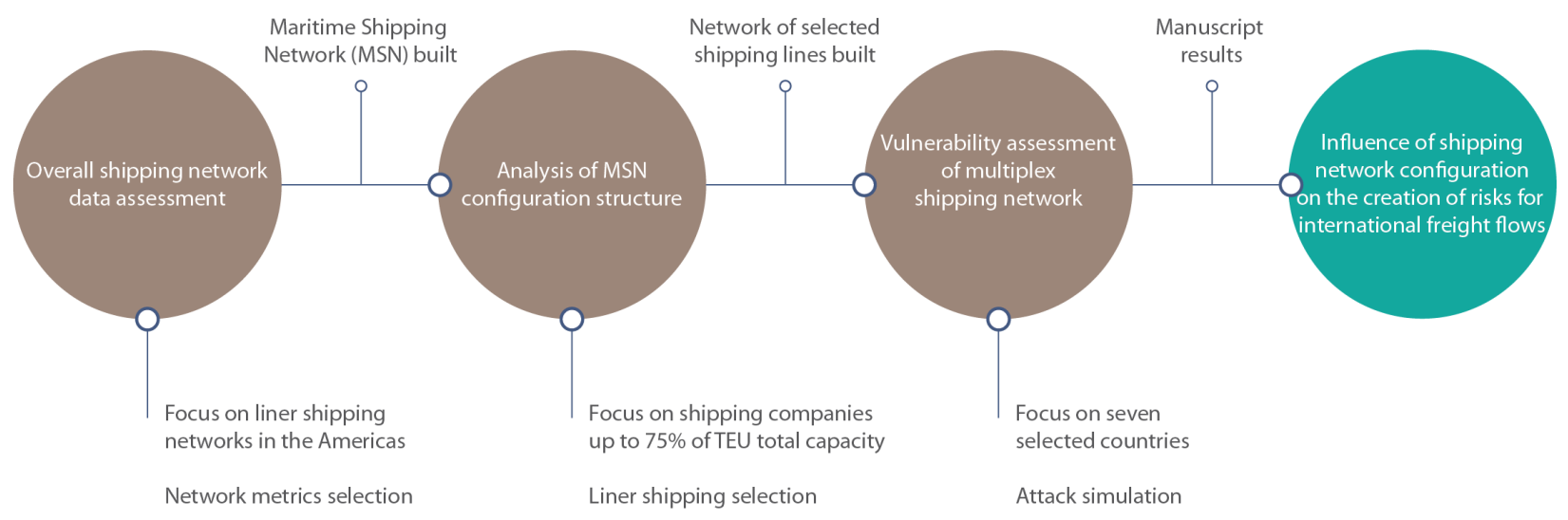

Figure 1. Diagram illustrating the methodology applied

To build the multiplex shipping network, data on both intra and extra liner shipping services in the Americas was gathered from Containerization International (2012), for the 32 countries and the 139 container ports located in them. These data were inputted into Gephi, an open software for network visualisation and analysis (Bastian et al., 2009), to produce the Maritime Shipping Network or 'MSN', which can be defined as the directed network of all shipping services calling at ports in the Americas. Unlike most of the available literature (Kaluza et al., 2010; Ducruet and Notteboom, 2012; Pais et al., 2012) which use undirected networks, this paper takes into account the directionality of links. Indeed, due to the differences in shipping service routing, the number and weight of links between countries $i$ and $j$ is frequently not the same as between countries $j$ and $i$. Therefore, in order to more accurately reflect the reality of shipping services, both inbound and outbound services were considered, allowing us to build an asymmetric matrix for network analysis and better understand the structure of the maritime network. The MSN contained 2,028 links between country pairs. Variables on the availability number of connections - and the quality - the frequency and capacity of connections - of maritime transport services were used to measure the strength of such links (Burghouwt and Redondi, 2013). For each country, data was gathered on containership deployment, container carrying capacity, and service 
frequency (Wilmsmeier et al., 2006; Ducruet and Notteboom, 2012). These variables were used to estimate the strength or capacity of the link for the country pair ij. Links were weighted according to the following formula:

$$
W_{i j}=\sum_{s=1}^{N_{i j}}\left(V_{s}^{i j} Q_{s}^{i j} F_{s}^{i j}\right)
$$

where $W_{i j}$ was total weight of link $i j$ - the link joining countries $i$ and $j$ - and measured in TEUs, $N_{i j}$ was the total number of services in link $i j, V_{s}^{i j}$ was average vessel size deployed in service $s$ for link $i j, Q_{s}^{i j}$ was the number of vessels deployed in service $s$ for link $i j$, and $F_{s}^{i j}$ was the annual frequency with which service $s$ links two given countries $i$ and $j$. Therefore, the total weight of each link $i j$ was the result of the sum of all services $s$ deployed between countries $i$ and $j$. According to Lam and Yap (2011), despite the fact that detailed information on the actual load of each container and its precise origin and destination is not publicly available, this way of calculating links weight can reveal the connectivity between countries in a systematic and quantifiable manner. Indeed, the literature suggests that due to the high correlation between container throughput and port hierarchies measured via vessel movements, this can be a reasonable proxy for actual links weight (Xu et al., 2015).

After building the MSN and with the purpose of analysing the structure of the multiplex network of maritime shipping lines in the Americas, the top (measured by TEU capacity as per Equation 1) 12 shipping lines were selected, making up 75\% of total TEU capacity available in the region in 2011 (Table $1)$.

\begin{tabular}{|l|c|}
\hline Shipping Line & $\begin{array}{c}\text { \% of total TEU } \\
\text { capacity in the } \\
\text { MSN }\end{array}$ \\
\hline MSC & 12 \\
\hline Maersk & 9.6 \\
\hline CSAV & 8.8 \\
\hline CMA-CGM & 7.9 \\
\hline Hamburg-Süd & 6.8 \\
\hline Evergreen & 6.3 \\
\hline Hapag-Lloyd & 5.9 \\
\hline APL & 4.3 \\
\hline ZIM & 4 \\
\hline COSCO & 4 \\
\hline NYK & 2.9 \\
\hline MOL & 2.5 \\
\hline Other & 25 \\
\hline Total & 100 \\
\hline
\end{tabular}

Table 1. Selected liner shipping companies 
Each shipping line's network was visualised using software for network visualisation. In line with the multiplex network approach applied in this paper, network analysis metrics were used to explore the topology of each shipping line network. Given that network metrics analyse network characteristics from a different perspective, a set of metrics was selected, namely: total degree; betweenness centrality; clustering coefficient; beta and gamma indices; and diameter. Total degree, network diameter, and beta and gamma indices were used to estimate the degree of completeness of each network. Clustering coefficient was used to estimate the degree of network concentration. Betweenness centralities was used to estimate the importance of a node in a network (Wang et al., 2011). Analysing the topology of the network is important to understand how vulnerable the network may be (Ducruet, 2016b). According to the literature in Network Science, higher network completeness - higher number of total links, higher clustering coefficient and lower network diameter - decreases network vulnerability (Barabasi, 2016). In turn, higher links concentration and disparity in links distribution may pose higher risks to network connectivity in the event of targeted attacks to the nodes with highest betweenness centrality (Albert et al., 2000; Woolley-Meza et al., 2011).

\begin{tabular}{|c|c|c|}
\hline Metric & Definition & Formula \\
\hline Total degree & $\begin{array}{l}\text { The total degree TD of a network is the sum of the degree centrality of all the } \\
\text { nodes in the network. The degree centrality }\left(C_{D}\right) \text { of a node } i \text { is the number of links } \\
\text { a node } i \text { shares with other nodes } j \text { in the network. The adjacent matrix } a_{i j}=1 \text { when } \\
\text { a direct link exists between nodes } i \text { and } j \text {, and } a_{i j}=0 \text { otherwise. It symbolizes the } \\
\text { importance of the node in a network. }\end{array}$ & $\begin{array}{l}C_{D}(i)=\sum_{j=1}^{n} a_{i j} \\
T D=\Sigma C_{D}\end{array}$ \\
\hline $\begin{array}{l}\text { Betweenness } \\
\text { centrality }\end{array}$ & $\begin{array}{l}\text { Betweenness centrality }\left(C_{B}\right) \text { refers to the extent to which a particular node } i \text { is } \\
\text { located on the shortest path connecting other nodes in the network. The shortest } \\
\text { path between two nodes is the path with the fewer number of links. } \sigma_{k j} \text { is the sum } \\
\text { of the number of all shortest paths between nodes } k \text { and } j \text {, and } \sigma_{k j}(i) \text { is the number } \\
\text { of the shortest paths that pass through node } i \text {. A node tends to have a more } \\
\text { important role in a network when it is on the shortest paths connecting many } \\
\text { node-pairs, as it may be in a position to broker or mediate connections between } \\
\text { these pairs. }\end{array}$ & $C_{B}(i)=\sum_{k \neq i \neq j \in N} \sigma_{k j}(i) / \sigma_{k j}$ \\
\hline $\begin{array}{l}\text { Average clustering } \\
\text { coefficient }\end{array}$ & $\begin{array}{l}\text { The clustering coefficient of a node } i \text { is the portion of actual links }\left(L_{i}\right) \text { between the } \\
\text { nodes }\left(k_{i}\right) \text { within its neighbourhood divided by the maximal possible links }\left(k_{i}(k i-\right. \\
1) / 2) \text {. A large } C_{i} \text { value means that the node has a more compact systems of } \\
\text { connections with its neighbours. The average clustering coefficient } C \text { of the whole } \\
\text { network is the average of all } C_{i} \text { over all nodes } i=1, \ldots, N \text {. In a fully-connected } \\
\text { network, } C \text { equals } 1 \text {. The larger the value of } C \text { is, the more likely nodes are to reach } \\
\text { one another within a short topological distance. }\end{array}$ & $\begin{aligned} C_{i} & =\frac{L_{i}}{k_{i}\left(k_{i}-1\right) / 2} \\
C & =\frac{1}{N} \sum_{i=1}^{N} C_{i}\end{aligned}$ \\
\hline Beta index & $\begin{array}{l}\text { The Beta index }(\theta) \text { is the average number of links }(l) \text { per node }(n) \text {. The higher } 6 \text {, the } \\
\text { more connected a network is. }\end{array}$ & $B=I / n$ \\
\hline Gamma index & $\begin{array}{l}\text { The Gamma index }(\gamma) \text { is the ratio of actual to maximal number of links }(l) \text {. The } \\
\text { higher } \gamma \text {, the more connected a network is. }\end{array}$ & $\gamma=2 I /[n(n-1)]$ \\
\hline Diameter & $\begin{array}{l}d_{i j} \text { is the number of links for the shortest path from } i \text { to } j \text { and the diameter } D \text { of a } \\
\text { network is defined as the maximum value of all } d_{i j} \text {. The lower the diameter, the } \\
\text { more connected a network is. }\end{array}$ & $D=\max d_{i j}$ \\
\hline
\end{tabular}

Table 2. Network metrics

As discussed in Section 2, the literature in maritime transportation shows that the hub-and-spoke configuration of maritime shipping networks renders networks more vulnerable to targeted attacks on such hubs (Woolley-Meza et al., 2011; Lhomme, 2016). To understand how vulnerable the multiplex 
shipping network in the Americas may be to attacks to critical hubs - and how those attacks could affect the different countries and their international freight flows -, we simulated 'attacks' to the seven countries with the highest betweenness degree in the MSN. An attack to a country made the country and its inbound and outbound links disappear from the network. Such an attack implies the shutdown of the ports in a country and could be caused by, for example, a natural disaster (hurricane, earthquake, etc.), a terrorist attack, political or civil unrest, or infrastructure/technical failures. There are several examples in the Americas where an event led to the closure of container ports in a country. Perhaps the most frequent ones in the region are related to extreme weather conditions, such as Tropical Storm Erika in 2015, which led to port closures in Dominican Republic, Haiti, Dominica and most of the small Caribbean islands; or Hurricane Matthew in 2016, which brought the ports of Jamaica and Bahamas to a halt. Strikes are other events that have affected port operations in the region, causing for example the closure of ports in Panama in 2012, Trinidad and Tobago in 2012, and Costa Rica in 2014.

In the simulation, an attack to a node generated an adjustment of nodes' links and position in the MSN and the twelve shipping line networks. The seven countries selected for the simulation were the ones with the highest betweenness in the MSN: United States (US), Panama, Jamaica, Trinidad and Tobago, Dominican Republic (DR), Colombia and Brazil. The impact of a targeted attack to each of the seven countries was studied both at the network and country levels. In total, 70 simulations - seven for the MSN with the removal of each hub, and 63 simulations for the 12 liner companies selected, according to whether the countries attacked were part of their networks or not - were conducted, generating 70 new networks. The set of network metrics presented in Table 2 was used to analyse the impact of the targeted attacks on both the MSN and each shipping line's network. The results of this analysis are detailed in the next section.

\section{Results and discussion}

The MSN - the single layered structure of the maritime shipping network in the Americas - was built and analysed first. Figure 2 shows the MSN in the Americas. In line with evidence from the literature that analysed the global maritime network (Hu and Zhu, 2009; Kaluza et al., 2010; Ducruet and Notteboom, 2012; Ducruet, 2017), the MSN presented a 'hub-and-spoke' structure and tested positive for a scale-free network with a power-law distribution of network links, meaning that a reduced number of countries had a large number of connections and that connectivity opportunities were unequally distributed among nodes (Figure 3). Capacity, which referred to links weight measured as per equation (1), was also unevenly distributed among links in the network. Less than $10 \%$ of the links concentrated $90 \%$ of the total capacity of the network. As shown in Figure 2, the links between US and Panama, US and Canada, US and Jamaica, and Brazil and Argentina, were the links with the highest weight in the network. 


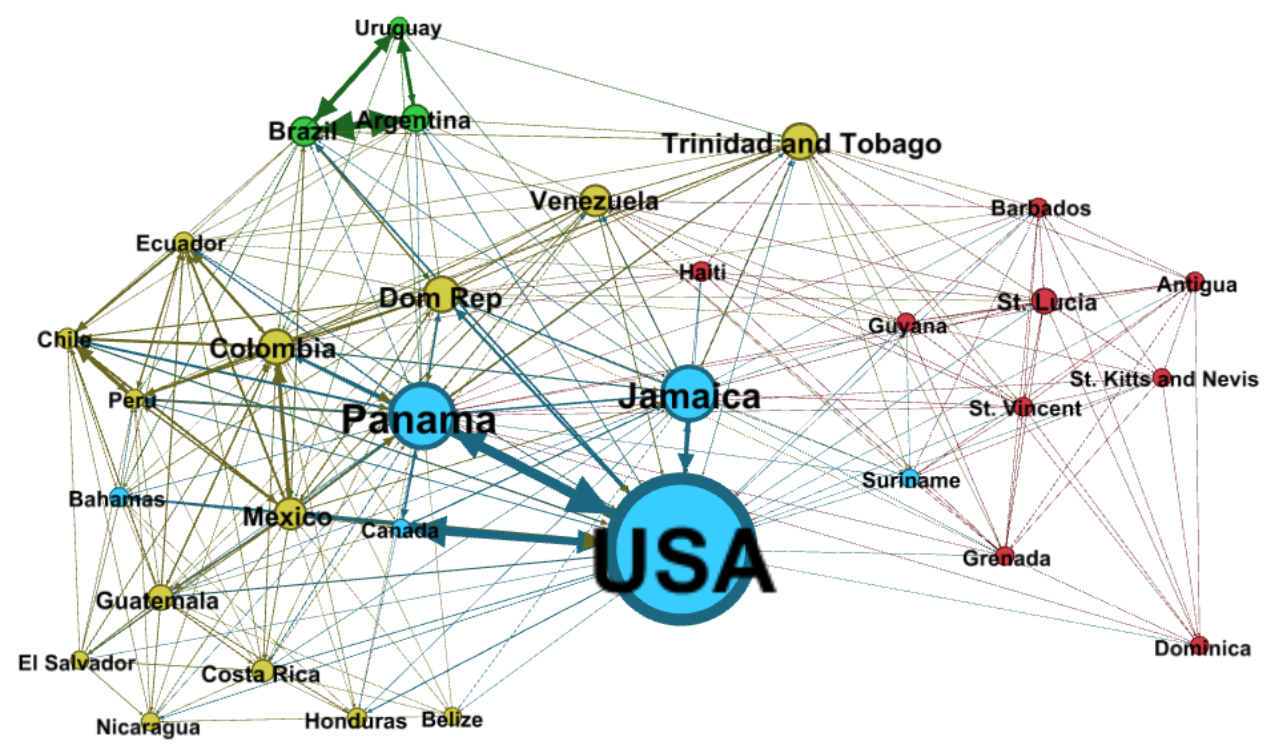

Figure 2. MSN*

*Node's size according to betweenness centrality. Node's colour according to maritime community. Links weight according to capacity of shipping connection between countries (total TEUs in 2011).

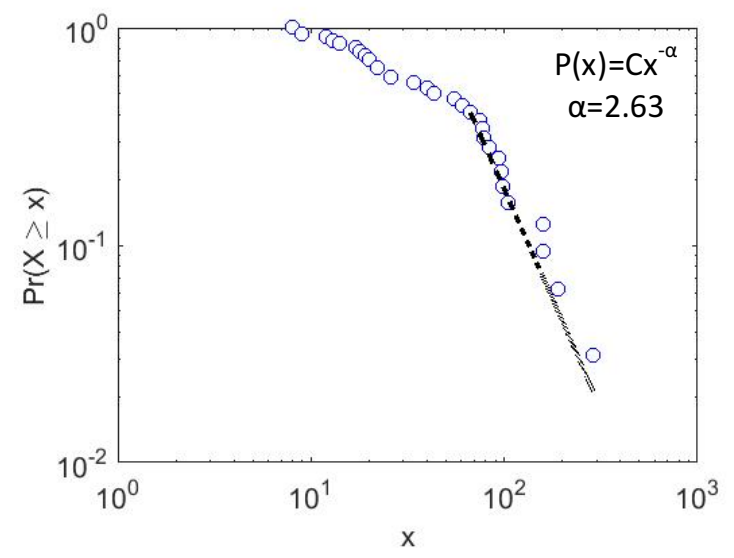

Figure 3. Testing for power-law distribution in the MSN*

* A quantity $x$ obeys a power law if it is drawn from a probability distribution $\mathrm{P}(\mathrm{x})=\mathrm{Cx}{ }^{-\alpha}$, where $\mathrm{C}$ is a constant parameter of the distribution known as the exponent or scaling parameter. The scaling parameter typically lies in the range $2<\alpha<3$ (Barabasi, 2016).

Although the literature has evidenced that hub-and-spoke networks are more efficient for network connectivity - most of the nodes in the network can be reached within a few hops - it has also been shown that these networks are more vulnerable to targeted attacks (Albert et al., 2000). The results of the network metrics (Table 2) applied to the MSN evidenced a low network completeness, with a beta index of 11.22/31, a gamma index of $0.33 / 1$, a diameter of 3 and an average clustering coefficient of 
0.63/1. In line with the hub-and-spoke organisation of the MSN, a few nodes - US, Panama, Jamaica, Trinidad and Tobago, DR, Colombia and Brazil - showed higher degree and betweenness centralities. A priori, and following the evidence found in the literature (Albert et al., 2000; Woolley-Meza et al., 2011), these results would suggest a high vulnerability of the MSN in the event of targeted attacks to its hubs. This will be further analysed in the pages that follow when we simulate 'attacks' to selected countries.

The analysis of the origin and destination of links in the MSN showed that countries in the network were mainly connected to their geographic neighbours and regional/global hubs. Figure 4 provides a geographical representation of the main MSN linkages that illustrates the tight geographical connection. Taking into account that the main trade partners for countries in the region are the US and Canada (Blyde, 2014), the 'hub-and-spoke' structure of the MSN made international freight flows transit through third countries before getting to their destination. These third countries were neighbours in a given MSN community, regional connectors and global hubs. Four communities emerged in the MSN: (i) a community gathering two North American countries (US and Canada) with countries that acted as hemispheric hubs in the MSN (Panama and Jamaica); (ii) a community gathering countries in the Southern Cone with shores on the Atlantic coast (Brazil, Argentina and Uruguay); (iii) a community gathering Caribbean countries; and (iv) a community gathering countries in Central America and the West Coast of South America (WCSA) (Figure 2). Communities were identified by applying the 'Louvain method' for community detection in Gephi (Blondel et al., 2008). The presence of communities in the MSN can certainly provide an advantage for the smoothness of freight flows between countries that belong to the same community, ensuring the availability of frequent shipping services among them. However, as mentioned above, evidence shows that often global supply chains in the Americas link buyers located in the US with suppliers located in the rest of the countries (Blyde, 2014). Under these circumstances, the presence of communities in the MSN may pose challenges for the seamless transportation of international goods between trade partners. Indeed, due to the configuration of shipping services, containerships often subsequently call at ports in neighbouring countries. For example, containerships with goods exported from Chile, often had to call first at ports in Peru (Callao) and Ecuador (Guayaquil), and Colombia (Buenaventura) before arriving to their international destination in the US. Therefore, the performance of ports and the business environment in community neighbours can certainly impact the smooth flow of freight between international trade partners. 


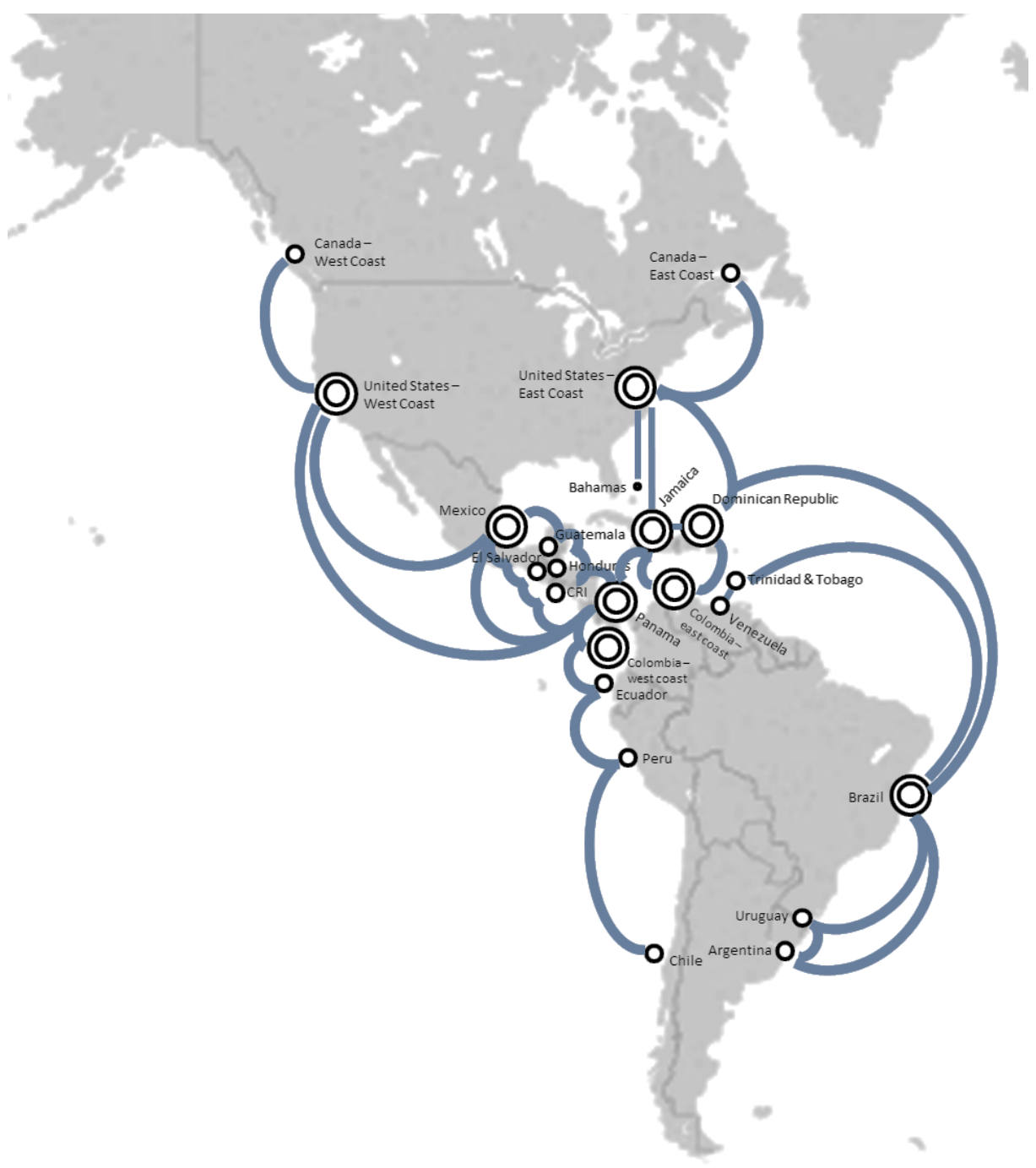

Figure 4. Geographical representation of the main MSN linkages

Among community neighbours, certain countries played a more critical role since they acted as connectors between communities, thus allowing countries in the different communities to be connected not only to their neighbours, but also to countries in other communities. This was revealed by their higher betweenness centrality. For example, Brazil emerged as a critical connector between the Southern Cone community and the rest of the network. Likewise, Trinidad and Tobago acted as the bridge between the Caribbean community and the other communities in the MSN, and Colombia played the regional hub role for WCSA. In turn, US, Panama and Jamaica acted as global hubs in the MSN. Their presence was critical for global connectivity since they connected to different communities, to global and regional hubs, and to individual countries, enabling connection among all the nodes they were connected to. Due to the 'hub-and-spoke' structure of the MSN, the position of these countries as global and regional hubs provided them with an advantage in terms of reaching their trade partners in the fastest and smoothest way. Indeed, their products could reach their destination markets with fewer 
steps and transhipments than the products of firms located in countries with a less central position. In contrast, the flow of products from more peripheral countries in the MSN depended not only upon transport reliability in the given country, but also upon events occurring in regional and global hubs, as well as in countries in the same community. Therefore, the configuration of a hub-and-spoke network makes the international freight flows of peripheral countries more exposed to disruption risks than those of other countries in the same community, regional connectors and global hubs.

Having analysed the MSN in the Americas, we wanted to assess the extent to which the organisation of the multi-layered shipping network posed risks to international freight flows in the Americas. Figure 5 shows the structure of the 12 main shipping lines in the Americas.

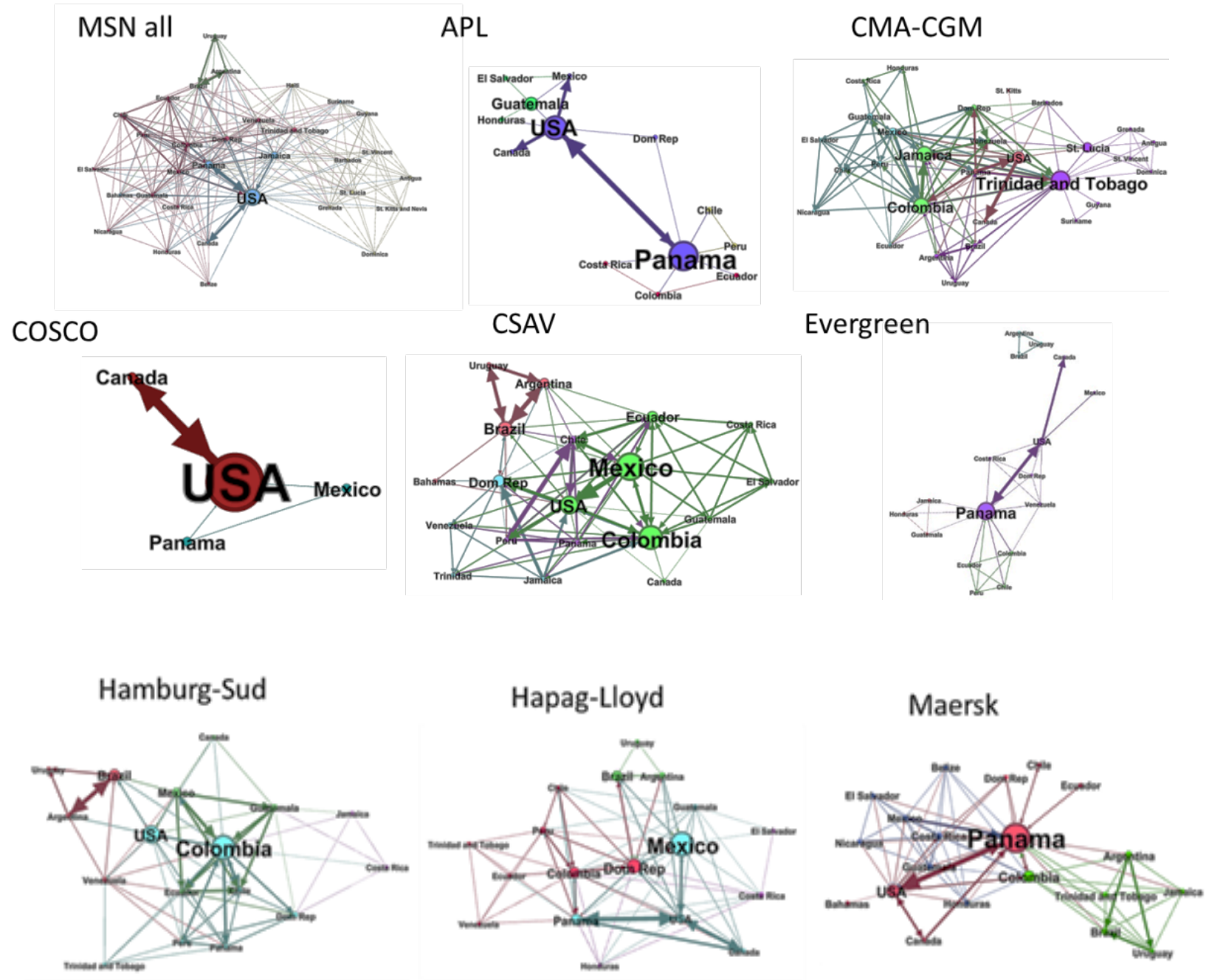

Figure 5. Main shipping lines in the Americas* 
$\mathrm{MOL}$
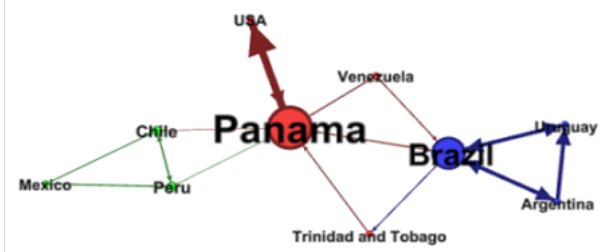

NYK

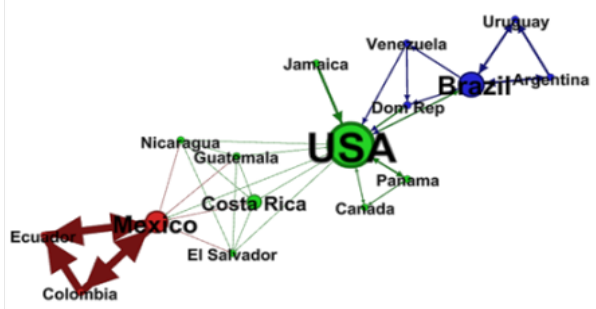

MSC

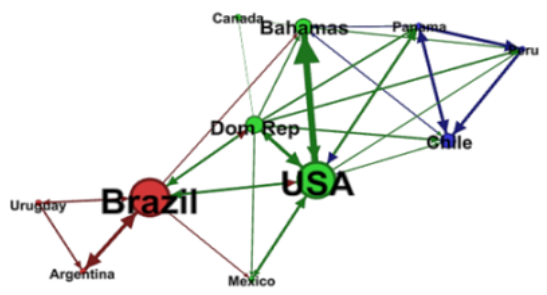

ZIM

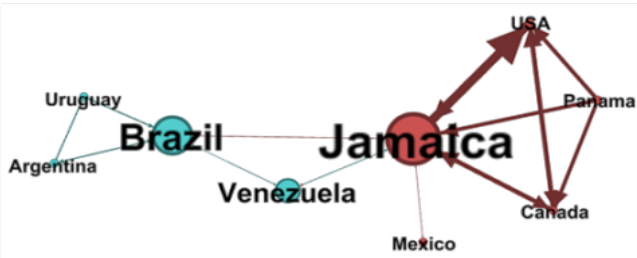

Figure 5. Main shipping lines in the Americas (cont.)*

*Nodes'size and labels size according to betweenness centrality. Links weight according to weight of connections between countries. Links colour according to community.

The network analysis metrics selected and summarised in Table 2 were used to explore the characteristics of each shipping line network (Table 3).

\begin{tabular}{|l|c|c|c|c|c|c|c|c|c|c|c|c|c|}
\hline & MSN & APL & $\begin{array}{c}\text { CMA- } \\
\text { CGM }\end{array}$ & CSAV & COSCO & Evergreen & $\begin{array}{c}\text { Hamburg- } \\
\text { Süd }\end{array}$ & $\begin{array}{c}\text { Hapag- } \\
\text { Lloyd }\end{array}$ & Maersk & MOL & MSC & NYK & ZIM \\
\hline Nodes & 34 & 13 & 29 & 19 & 4 & 17 & 17 & 18 & 20 & 10 & 11 & 16 & 9 \\
\hline $\begin{array}{l}\text { Total } \\
\text { degree }\end{array}$ & 393 & 32 & 167 & 111 & 5 & 52 & 97 & 102 & 117 & 22 & 40 & 47 & 21 \\
\hline $\begin{array}{l}\text { Avg. } \\
\text { luster. } \\
\text { coeff. }\end{array}$ & 0.639 & 0.691 & 0.605 & 0.639 & 0.292 & 0.662 & 0.637 & 0.627 & 0.66 & 0.633 & 0.671 & 0.708 & 0.587 \\
\hline $\begin{array}{l}\text { Beta } \\
\text { index }\end{array}$ & 11.22 & 2.46 & 5.75 & 5.84 & 1.25 & 3.05 & 5.706 & 5.66 & 5.85 & 2.2 & 3.63 & 2.93 & 2.33 \\
\hline $\begin{array}{l}\text { Gamma } \\
\text { index }\end{array}$ & 0.33 & 0.205 & 0.206 & 0.325 & 0.417 & 0.191 & 0.357 & 0.333 & 0.308 & 0.244 & 0.364 & 0.196 & 0.292 \\
\hline Diameter & 3 & 4 & 4 & 3 & 2 & 3 & 4 & 4 & 4 & 4 & 4 & 4 & 4 \\
\hline
\end{tabular}

Table 3. Multiplex network structure of the MSN

The analysis showed that network properties of individual liner shipping companies differed from that of the MSN and among themselves. These results are line with the works of Kaluza et al. (2010) and Ducruet (2013 and 2017), which showed that a multiplex model better fits the different characteristics of maritime transportation, as well as with those of Cardillo et al. (2013), which showed that a multiplex model can better evidence the different structures of transport companies' networks. However, this 
paper provides an important contribution to the literature by analysing the multiple layers of the maritime network based on the different liner shipping companies' strategies, an analysis that to date has been missing.

For the liner shipping networks analysed here, results suggested there were networks as large as CMACGM's (29 nodes, 167 links), and as small as COSCO's (4 nodes, 5 links). Some networks were more dense than the MSN (e.g. CSAV, Cosco, Hamburg-Süd), while others were less dense (e.g. APL, Evergreen, NYK) (Table 3). Average connectivity opportunities at the node level (beta index) in the networks of CMA-CGM, CSAV, Hamburg-Süd and Maersk more than doubled those in APL, COSCO, MOL and ZIM. Likewise, there were networks more clustered than the MSN (e.g. APL, MSC), while others presented a very low level of clustering (e.g. COSCO, ZIM) (Table 3). The differences in terms of network completeness would suggest that liner shipping networks have different degrees of vulnerability. This will be discussed later when we present the results of the simulations. In turn, network visualisation and the betwenness centrality metrics showed that nodes occupied different positions in each network (Figure 5). For example, the US and Panama played key roles in the APL network; Colombia and Trinidad and Tobago were central nodes in the CMA-CGM network; and Brazil and Jamaica were critical in the ZIM network. Moreover, the most important links in the networks in terms of capacity did not match either. For example, while the link between US and Panama had the highest weight in the APL, Evergreen, Maersk, and MOL networks, it had little importance in the CSAV, Hamburg-Sud, MSC, and NYK networks (Figure 5). As is shown below, these differences determined how dependent and vulnerable liner shipping networks were to simulated attacks.

Further analysis of the multiplex liner shipping network in the Americas showed that certain countries had higher dependency from specific liner shipping companies. This was because either a low number of companies called at their ports and/or a reduced number of companies provided a large share of available capacity for such countries. For example, in the case of Jamaica, one shipping line (ZIM) provided near $40 \%$ of available capacity. Together with CMA-CGM (21\%) and CSAV (20\%), three shipping lines provided $80 \%$ of available capacity. In the case of DR, two shipping lines provided $52 \%$ of available capacity: MSC (28\%) and CSAV (24\%). In the case of Chile, three shipping lines provided nearly twothirds of available capacity: CSAV (26\%), Hamburg-Süd (19\%) and MSC (18\%). Likewise, in the case of Costa Rica and Honduras three lines provided up to two-thirds of available capacity. For Costa Rica, these companies were: CMA-CGM (13.3\%), CSAV (29.3\%) and Maersk (23.6\%). For Honduras, the companies were: Seaboard (25.8\%), CMA-CGM (19\%) and CLS (18.3\%). As a result, international freight flows from these countries depended on the port choice decisions of the liner shipping companies calling at their ports. For example, exports of electronic and pharmaceutical products from Costa Rica mostly depended on the business strategies and network performance of CMA-CGM, CSAV and Maersk to reach their buyers in the US.

The analysis of the multiplex liner shipping network in the Americas also showed that certain maritime/geographic areas were highly dependent upon specific liner shipping companies. In the case of WCSA, three shipping lines provided $60 \%$ of available capacity: CSAV (25\%), Hamburg-Süd (19\%) and MSC (18\%). In the case of the Southern Cone, although it was much less concentrated than the WCSA, 
four shipping lines accounted for $60 \%$ of total TEUs available for the area. In the west coast of Central America (WCCA), one shipping line (Hamburg-Süd) provided $42 \%$ of available capacity. When considering the two main liner shipping companies in the area (including CSAV, 22\%), they accounted for nearly two-thirds of available capacity. Finally, in the Caribbean two shipping lines provided two-thirds of available capacity: CMA-CGM (32\%) and CSAV (34\%). The only exception on liner company dependency was the east coast of Central America (ECCA), where with 4 shipping lines providing $50 \%$ of available capacity, lower concentration was evident.

Taking into account the configuration of the maritime shipping networks, we next analysed how vulnerable freight flows from a given country were to events disrupting the network of shipping services in the Americas, even if those events occurred in third countries. Similar to the case of the MSN, the hub-and-spoke strategies adopted by the shipping lines create a hierarchy among ports, with hub ports having a pivotal role for the overall connectivity of each shipping network. This corresponds to the fact that the main shipping lines in the Americas are also major international players with global shipping strategies, which use hub-and-spoke networks to improve their global efficiency and profitability (McCalla et al., 2005; Fremont, 2007). Such a strategy can be evidenced in the different network configurations shown in Figure 5. This is particularly evidenced through the higher betweenness centrality of a small number of nodes in each of the individual liner shipping networks. For example, in the case of the CMA-CGM network, the hubs in the Americas are Trinidad and Tobago, Colombia and Jamaica; for Evergreen, the hubs are Panama and the US; for Maersk, Panama; for MOL, Panama and Brazil; and for ZIM, Jamaica and Brazil.

In line with available evidence on complex networks (Albert et al., 2000; Woolley-Meza et al., 2011), results from the 70 simulations conducted showed that, in a hub-and-spoke strategy, the vulnerability of the network depends on which node is attacked. In addition, the specific position of a node in a network made it more or less exposed to attacks in other nodes or parts of the network. For example, since Jamaica was a critical hub for the ZIM network, the simulated attack to this country led to a significant damage to ZIM's network, with a significant reduction of links and nodes in the network compared to the simulated attacks to other countries. This is graphically illustrated in Figure 6 . The results of the other 70 networks generated through the simulations are reported here but not illustrated due to space limitations. Instead, the simulated attack to Jamaica had little impact on the NYK network since it was a peripheral node in the NYK network, and had no importance at all for the MSC network, since Jamaica was absent from such network. Likewise, Evergreen's network was significantly affected by the simulated attack to Panama, when it lost $85 \%$ of its links, but was largely unaffected by the attack to Brazil, when it lost less than $1 \%$ of its links (Table 4).

As a consequence of the different roles countries had in each liner shipping network, simulated attacks to the countries selected had different impacts. For example, when taking into account total number of links lost with the removal of a selected country from the network - or the decrease in network completeness -, results showed that a failure in Brazil affected more the MOL network than any other shipping company network; Colombia affected more the Hamburg-Süd network; DR affected more the MSC network; Jamaica affected more the ZIM network; Panama affected more the Evergreen network; 
Trinidad and Tobago affected more the CMA-CGM network; and the US affected more the COSCO and NYK networks than any other shipping company network (Table 4). These results can provide an important insight to both international trade and supply chain risk management strategies. Due to the fact that the structure of shipping routes does not entirely overlap trade patterns (Ducruet and Notteboom, 2012; Calatayud et al., 2017), often exports from a given country have to go through intermediary ports and countries - either because of the service routing or the need for transhipment before arriving at destination. Therefore, business environment and the performance of ports in intermediary ports and countries can certainly impact the smooth flow of goods among international trade partners. In this context, results show that international freight flows from countries located in maritime regions with higher dependency on, for example, CMA-CGM services - e.g. Jamaica or the Caribbean community -, could be affected should disruptions occur at Port of Spain in Trinidad and Tobago. Likewise, international freight flows from countries with higher dependency on Hamburg-Süd services, such as Chile, could be at risk from disruptions to the ports of Buenaventura and Cartagena in Colombia.

ZIM's network in the Americas

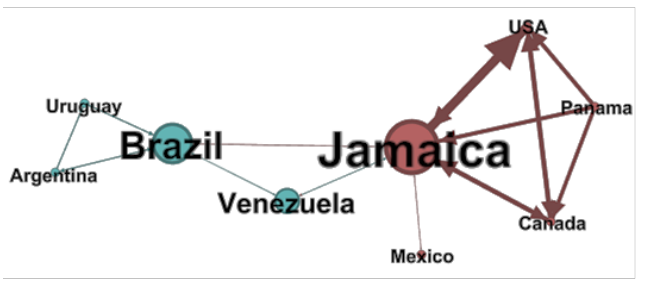

Simulated attack to Jamaica - Impact on ZIM's network

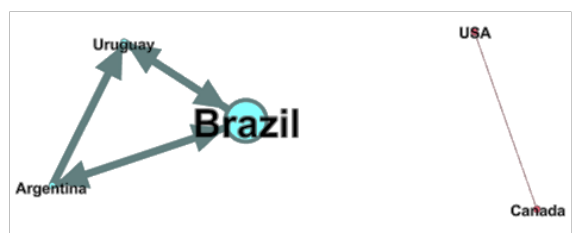

Simulated attack to Brazil - Impact on ZIM's network

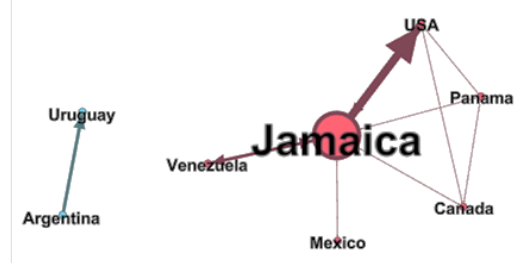

Simulated attack to Panama - Impact on ZIM's network

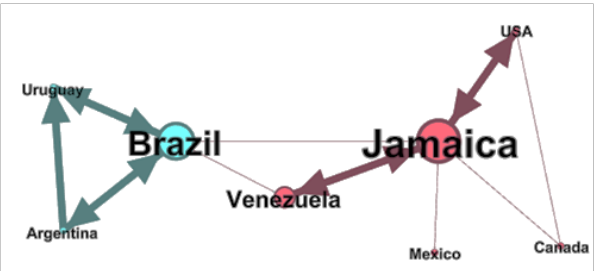

Simulated attack to the US - Impact on

ZIM's network

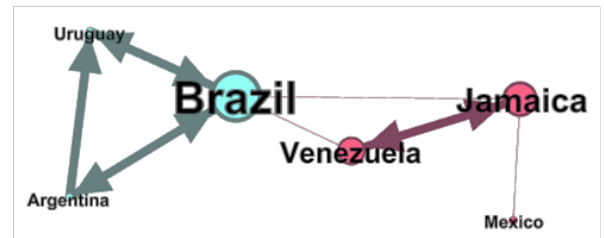

Figure 6. Simulated attacks to selected countries and impact on ZIM's network* 
*Nodes'size and labels size according to betweenness centrality. Links weight according to weight of connections between countries. Links colour according to community.

\begin{tabular}{|l|c|c|c|c|c|c|c|}
\hline & $\begin{array}{l}\text { \% change } \\
\text { no Brazil }\end{array}$ & $\begin{array}{l}\text { \% change no } \\
\text { Colombia }\end{array}$ & $\begin{array}{l}\text { \% change } \\
\text { no DR }\end{array}$ & $\begin{array}{l}\text { \% change } \\
\text { no Jamaica }\end{array}$ & $\begin{array}{l}\text { \% change } \\
\text { no Panama }\end{array}$ & $\begin{array}{l}\text { \% change } \\
\text { no T\&T }\end{array}$ & $\begin{array}{l}\text { change } \\
\text { no US }\end{array}$ \\
\hline MSN all & -12 & -19.3 & -11.5 & -17.8 & -21.6 & -29.3 & -38.7 \\
\hline APL & - & -18.8 & -9.4 & - & -59.4 & - & -40.6 \\
\hline CMA-CGM & -1 & -55.1 & -16.2 & -38.3 & -25.1 & -41.3 & -18.6 \\
\hline Cosco & - & - & - & - & -60 & - & -80 \\
\hline CSAV & -26.1 & -50.5 & -32.4 & -17.1 & -25.2 & - & -36 \\
\hline Evergreen & -9.6 & -40.4 & -15.4 & -17.3 & -84.6 & - & -21.2 \\
\hline Hamburg-Süd & -14.4 & -83.5 & -14.4 & -7.2 & -40.2 & -11.3 & -33 \\
\hline Hapag-Lloyd & -15.7 & -56.9 & -30.4 & - & -44.1 & -15.7 & -43.1 \\
\hline Maersk & -27.4 & -36.8 & -6.8 & -14.5 & -64.1 & -23.9 & -65.8 \\
\hline MOL & -45.5 & - & - & - & -59.1 & -13.6 & -9.1 \\
\hline MSC & -30 & - & -42.5 & - & -42.5 & - & -57.5 \\
\hline NYK & -29.8 & -38.3 & -17 & -2.1 & -12.8 & - & -72.3 \\
\hline ZIM & -33.3 & - & - & -71.4 & -23.8 & - & -42.9 \\
\hline
\end{tabular}

Table 4. Impact of attacks on networks size (links)*

*Cells highlighted in grey indicate the liner shipping network that was impacted the most when a given country was attacked, as a function of the percentage of links the liner shipping network lost.

We applied the network metrics selected and summarised in Table 2 to analyse the impact of targeted attacks on the MSN and the individual liner shipping networks. A lower number of total links, a higher network diameter, and lower beta and gamma indices indicate a negative effect of the targeted attack on network connectivity, therefore making it more difficult to reach nodes in the network. A lower clustering coefficient indicates a negative impact of the attack on network concentration, thus decreasing the density of ties between nodes in a network. At the global level of the MSN, among all the simulations conducted it was an attack to the US which had the highest impact on the network (Figure 7). Due to the role that the US had in the MSN as global connector, removing this country from the network substantially reduced global connectivity and network size. In fact, the total number of links decreased by nearly $40 \%$, the beta index by $31 \%$, and the gamma index by $21 \%$. In turn, network diameter increased by $33 \%$ and clustering coefficient by $38 \%$. Surprisingly, the country that had the second most important impact on the MSN when it was removed from the network was Trinidad and Tobago (Figure 8): links decreased by $29 \%$ and the beta index by $17 \%$. Network diameter increased by $33 \%$ and clustering coefficient by $23 \%$. Looking closer to the MSN structure, the relevance of Trinidad and Tobago for global connectivity is explained by the critical role the country played as a connector for the Caribbean and Southern Cone communities to the rest of the network. Overall, these results imply that countries that are international trade partners, and global supply chains with nodes in the Americas that involve products moving in maritime containers, should include in their risk assessments an 
evaluation of the extent to which they may be exposed to risks of delays or disruptions should ports in the main hubs be closed due to adverse weather conditions, strikes, national threats, etc.

When analysing the impact of the simulated attacks on the connectivity of each of the 32 countries, results showed that the countries with highest vulnerability (in terms of loss of $20 \%$ of total number of links or more) were: Argentina - whose connectivity was highly impacted by attacks on five of the selected countries - followed by Haiti, Suriname and Uruguay, whose connectivity was impacted by attacks on four countries. Instead, the countries with the highest resilience were Brazil, Colombia, DR, Guatemala, Mexico, and the US, whose connectivity went below the threshold of $20 \%$ of links lost just once among the different simulations conducted. This suggests that international freight flows from the first group of countries could be more exposed to risks of disruptions in maritime shipping services than international freight flows from the second group of countries, which would see their flow of products less affected by disruptions in the MSN.

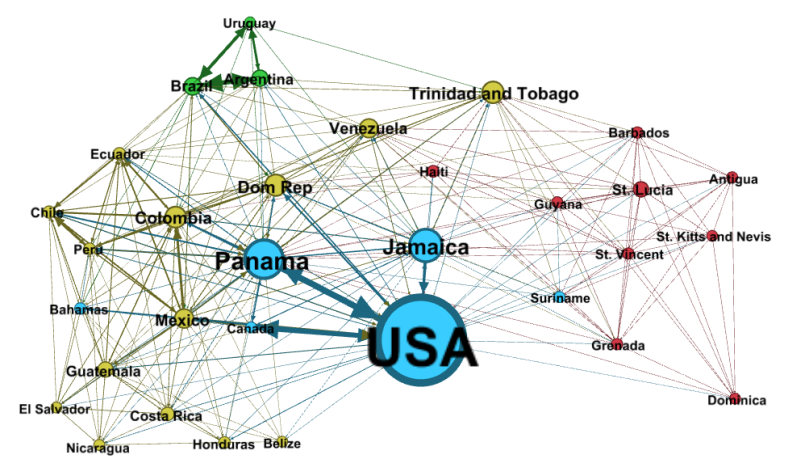

(i)

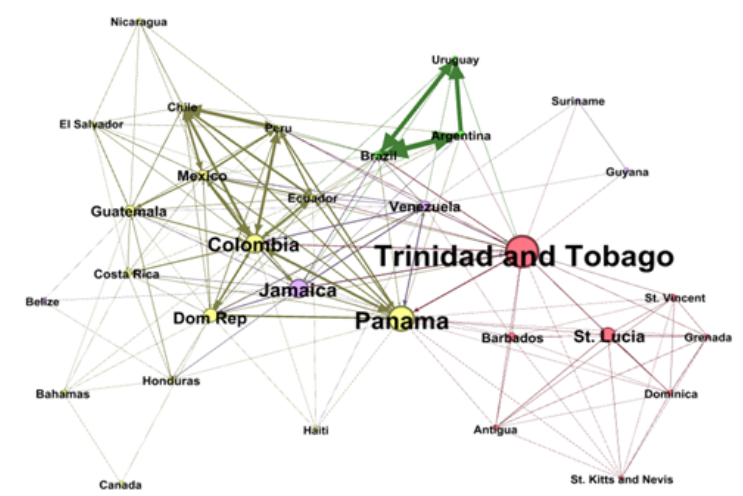

(ii)

Figure 7. Simulated attack to the US and impact on the MSN*

*Nodes'size and labels size according to betweenness centrality. Links weight according to weight of connections between countries. Links colour according to community. (i) Before the attack; (ii) after the attack.

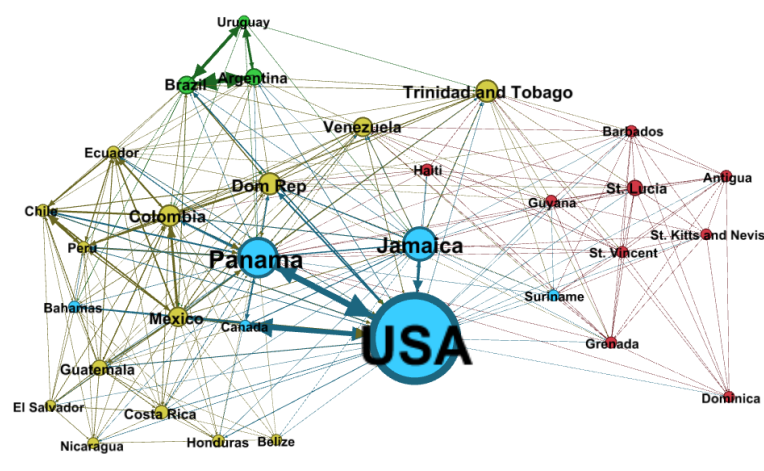

(i)

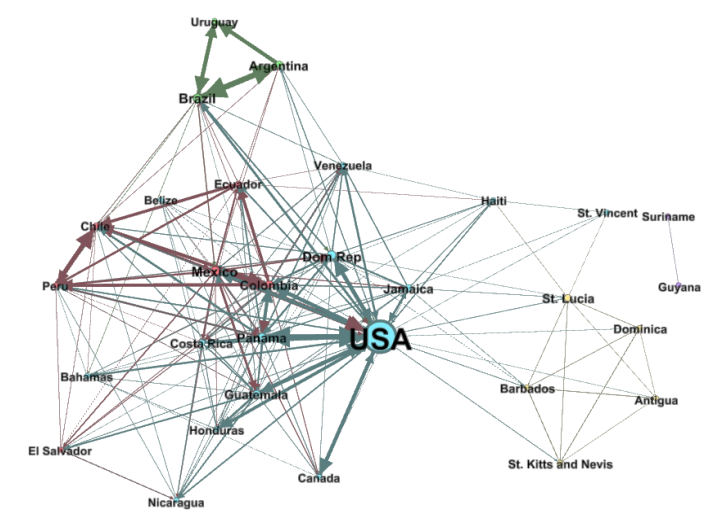

(ii)

Figure 8. Simulated attack to Trinidad and Tobago and impact the MSN* 
*Nodes'size and labels size according to betweenness centrality. Links weight according to weight of connections between countries. Links colour according to community. (i) Before the attack; (ii) after the attack.

Communities showed different degrees of vulnerability according to the shipping line serving them and the role neighbours in the community and hubs played in the liner shipping network. For example, WCSA depended on the services from three main shipping lines: CSAV (25\%), Hamburg-Süd (19\%) and MSC (18\%). According to the results shown in Table 4 regarding the number of total links lost after an attack, in the case of CSAV, services were more vulnerable to disruptions in Colombia and Brazil. In the case of Hamburg-Süd, services were more vulnerable to attacks to Colombia and the US. Finally, in the case of MSC, services were more vulnerable to disruptions in Brazil, DR and the US. The Southern Cone community revealed a significant exposure to disruption in many countries, such as Brazil, Trinidad and Tobago, DR and Jamaica, suggesting high vulnerability to events occurring in different network hubs, even in those geographically located far from the community. As a consequence of attacks to different countries, countries in the Southern Cone were cut off or disappeared from the network. In the case of WCCA, two shipping lines provided $64 \%$ of available connections: Hamburg-Süd (42\%) and CSAV (22\%). Because of this, the community was particularly vulnerable to disruptions in Colombia, due to the configuration of both liner shipping networks. In the Caribbean two shipping lines provided two thirds of available capacity: CMA-CGM (32\%) and CSAV (34\%). Therefore, the community was more vulnerable to disruptions in Trinidad and Tobago (due to the special role this country had in the CMA-CGM network) and Jamaica (because of the role that the country had in the CSAV network).

Likewise, countries showed different levels of vulnerability to the simulated attacks according to the liner shipping companies calling at their ports and the structure of the companies' networks. For example, given that Jamaica was mainly served by ZIM (37\%), CMA-CGM (21\%) and CSAV (20\%) services, the firms located in this country were particularly exposed to the attacks in Brazil (see Figure 6 where the effect of an attack on Brazil is illustrated, disrupting the services to the Southern Cone community) and in Colombia. In the case of the firms located in DR, they were more vulnerable to disruptions in Brazil, Panama and the US because of the importance that MSC services (28\%) had in DR's total shipping services, and Brazil, Colombia and the US in the case of CSAV services (24\% of total DR's services). Being served by CSAV (26\%), Hamburg-Süd (19\%), and MSC (18\%), Chile proved to be vulnerable to disruptions in Colombia and Panama. In the case of Argentina and Uruguay, these countries proved to be highly dependent and vulnerable to shocks in Brazil. These results suggest that firms located in Chile, for example, should assess to what extent their operations may be exposed to disruptions at ports in Colombia and Panama, as well as to the networks of CSAV, Hamburg-Süd and MSC shipping lines.

Overall, the results of this paper evidence the importance of taking into account the structure of maritime networks as a source of risk for international freight flows and global supply chains. Indeed, due to the configuration of shipping networks, containerships usually call at ports in neighbouring countries, and regional or global hubs before arriving to destination. Therefore, from a risk management perspective, the performance of ports and the business environment in intermediate countries can impact the smooth flow of freight among international trade partners. In addition, the high market 
concentration by shipping lines serving a particular country is another source of risk. For the various stakeholders interested in the movement of freight using international shipping networks, awareness should be the first step to mitigate risk from shipping line networks. Further actions for supply chain managers should include improving visibility and supply chain integration with not just port operators, as suggested by the literature (Panayides and Song, 2008), but also with liner companies. This is even more important in a situation where liner companies are increasingly integrating vertically with ports and land transportation companies and becoming logistics service providers (Fremont and Soppe, 2004). As part of the risk mitigation actions and visibility improvement in the maritime legs of supply chains, early warning systems could be implemented in order to identify potentially disruptive events in both intermediary countries and shipping lines, and enhance preparedness and response capabilities. From the policy perspective, actions could include fostering investment for a more efficient and resilient port infrastructure, as well as increasing dialogue and cooperation with other countries in the Americas as a means to coordinate efforts around infrastructure investment, connectivity, regulation and trade facilitation, and emergency preparedness.

\section{Conclusion}

Using multiple network modelling and analysis, this paper provided evidence that the structure of the multi-layered maritime shipping network created different levels of vulnerability for international freight flows, according to the different positions countries occupied in the network. In line with available literature in the transportation field, it was shown that a multiplex model better represents the real situation, as it can more effectively illustrate the different structures of liner companies' networks. As supply chains become more international and complex, with partners located in different countries and subject to different business environments, dependence on maritime transportation and shipping strategies increases, along with the risks to disruptions in such networks. Given the challenges that these disruptions pose to supply chain performance and management, firms should be aware of how a given country's position in the MSN and the strategies of the liner shipping companies servicing it can impact them and include this factor in their supply chain risk management strategies. In this context, risk mitigation actions should seek to increase visibility and integration with liner companies. Early warning systems can identify possible problems in intermediate countries and shipping lines, and provide supply chain partners with wider margins of time and ability to maneuver so as to avoid or, at least, minimize disruptions in the chain.

Furthermore, the results of this research can be useful for policy-making. A country's transport and trade strategies cannot be designed in isolation from the transport contexts (or networks) the country is embedded in - such strategies need to acknowledge the level of dependency from other actors and be able to minimise the resulting risks. Although governments can only moderately influence the strategies of liner shipping companies, they can play an important role in facilitating actions to mitigate the risks of international trade disruptions. For example, they can set the standards for and/or provide infrastructure resilient to natural disasters. They can also endeavor to provide liner companies with a 
predictable business environment and legal frameworks under which operate. Given the interdependency of countries in the MSN, governments can also develop strategies at the wider regional / pan national level as a means to coordinate efforts around investment, regulation and trade facilitation, and security / preparedness.

Further research could focus on collecting data for a broader period of time in order to analyse any variation over time in liner shipping strategies as well as the countries' position in the multi-layered maritime transport network. Further research could also focus on applying the proposed approach to other regions or country groups, and to the individual ports in the network. This would enable comparison of dependency and vulnerability levels among different regions, country groups or ports, as well as provision of input for decision-making concerning policy-makers and global supply chains operating in a broader group of countries. Another area for future investigations could be the likelihood of an economy or a port of suffering from disruptions in shipping services. Finally, research could also focus on identifying policy and regulatory actions that mitigate vulnerability from liner shipping disruptions and, in general, the relation between network regulation policy and vulnerability in this and other sectors.

\section{References}

1. Acciaro, M and Serra, P. (2013), "Maritime Supply Chain Security: A Critical Review", in International Forum on Shipping, Ports and Airports proceedings of the international conference in Hong Kong, 2013, Hong Kong Polytechnic University, pp. 636-651.

2. Albert, R., Jeong, H. and Barabasi, A. (2000), "Error and attack tolerance in complex networks", Nature, Vol. 406, pp. 378-382.

3. Barabasi, A. (2016), Network Science, Cambridge University Press, Massachusetts, MA.

4. Barabasi, A. (2012), "The network takeover", Nature Physics, Vol. 8 No.1, pp. 14-16.

5. Barabasi, A. and Albert, R. (1999), "Emerging of scaling in random networks", Science, No. 286, pp. 509-512.

6. Bastian, M., Heymann, S. and Jacomy M. (2009), “Gephi: An Open Source Software for Exploring and Manipulating Networks", paper presented at the $3^{\text {rd }}$ National AAAl Conference on Weblogs and Social Media, San Jose, CA.

7. Blondel, V., Guillaume, J., Lambiotte, R. and Lefebvre, E. (2008), "Fast unfolding of communities in large networks", Journal of Statistical Mechanics: Theory and Experiment, Vol. 10, P10008 (12pp).

8. Blonigen, B.A. and Wilson, W.W. (2013), "The growth and patterns of international trade", Maritime Policy \& Management, Vol. 40 No.7, pp. 618-635.

9. Blyde, J. (2014), Synchronized Factories: Latin America and the Caribbean in the Era of Global Value Chains, Inter-American Development Bank, Washington D.C.

10. Bogataj, D. and Bogataj, M. (2007), "Measuring the supply chain risk and vulnerability in frequency space", International Journal of Production Economics, Vol. 108 No. 1-2, pp. 291-301. 
11. Burghouwt, G., and Redondi, R. (2013), "Connectivity in air transport networks: Models, measures and applications", Journal of Transport Economics and Policy, Vol. 47, pp. 35-53.

12. Calatayud, A., Palacin, R., Mangan, J., Jackson, E. and Ruiz-Rua, A. (2016), “Understanding connectivity to international markets: a systematic review", Transport Reviews, Vol. 36 No. 6 , pp. 713-736.

13. Calatayud, A., Mangan, J. and Palacin, R. (2017), "Connectivity to international markets: a multilayered network approach", Journal of Transport Geography, Vol. 61, pp. 61-71.

14. Cardillo, A., Zanin, M., Gomez-Gardenes, J., Romance, M., del Amo, A.J.G. and Boccaletti, S. (2013), "Modeling the multi-layer nature of the European Air Transport Network: Resilience and passengers re-scheduling under random failures", European Physical Journal-Special Topics, Vol. 215 No.1, pp. 23-33.

15. Christiansen, M., Fagerholt, K., Nygreen. B. and Ronen, D. (2013), "Ship Routing and Scheduling in the New Millennium", European Journal of Operations Research, No. 228, pp. 467-483.

16. Christopher, M. and Holweg, M. (2011),"“Supply Chain 2.0”: managing supply chains in the era of turbulence", International Journal of Physical Distribution \& Logistics Management, Vol. 41 No. 1 , pp. 63-82.

17. Containerization International (2012), Yearbook 2011, Informa Cargo, London.

18. Creazza, A., Dallari, F. and Melacini, M. (2010),"Evaluating logistics network configurations for a global supply chain", Supply Chain Management: An International Journal, Vol. 15 No. 2, pp. 154-164.

19. De Domenico, M., Sole, A., Omodei, E., Gomez, S. and Arenas A. (2015), "Centrality in Interconnected Multilayer Networks", Nature Communications, No. 6, 6868.

20. Djankov, S., Freund, C. and Pham, C.S. (2010), "Trading on time", Review of Economics and Statistics, Vol. 92 No. 1, pp. 166-173.

21. Ducruet, C. (2013), "Network diversity and maritime flows", Journal of Transport Geography, Vol. 30, pp. 77-88.

22. Ducruet, C. (2014), "Mapping global maritime flows and port hierarchies since the late nineteenth century", paper presented at Conference of the International Association of Maritime Economists, 15-18 July, Norfolk, VA.

23. Ducruet, C. (Ed.) (2016a), Maritime networks: spatial structures and time dynamics, Routledge, New York, NY.

24. Ducruet, C. (2016b), "The polarization of global container flows by interoceanic canals: geographic coverage and network vulnerability", Maritime Policy \& Management, Vol. 43, pp. 242-260.

25. Ducruet., C. (2017), "Multilayer dynamics of complex spatial networks: the case of global maritime flows (1977-2008)", Journal of Transport Geography, Vol. 60, pp. 47-58.

26. Ducruet, C. and Lugo, I. (2013), "Structure and Dynamics of Transportation Networks: Models, Methods, and Application", in Rodrigue, J.P., Notteboom, T. and Shaw, J. (Eds.), The SAGE Handbook of Transport Studies, SAGE Publications Ltd., London, pp. 347-364. 
27. Ducruet, C. and Zaidi, F. (2012), "Maritime constellations: a complex network approach to shipping and ports", Maritime Policy and Management, Vol. 39 No. 2, pp. 151-168.

28. Ducruet, C. and Notteboom, T. (2012), "The worldwide maritime network of container shipping: Spatial structure and regional dynamics", Global Networks, Vol. 12 No. 3, pp. 395-423.

29. Ducruet, C., Rozenblat, C. and Zaidi, F. (2010), "Ports in multi-level maritime networks: evidence from the Atlantic (1996-2006)", Journal of Transport Geography, Vol. 18 No. 4, pp. 508-518.

30. Earnest, D., Yetiv, S., and Carmel, S. (2012), "Contagion in the Transpacific Shipping Network: International Networks and Vulnerability Interdependence", International Interactions, Vol. 38 No. 5, pp. 571-596.

31. Feng, M., Mangan, J. and Lalwani, C. (2012), "Comparing port performance: Western European versus Eastern Asian ports", International Journal of Physical Distribution and Logistics Management, Vol. 42 No. 5, pp. 490-512.

32. Fremont, A. (2007), "Global Maritime Networks: The case of Maersk", Journal of Transport Geography, Vol. 15, pp.431-442.

33. Fremont, A. and Soppe, (2004), "The Evolution of North-European Shipping Networks: from Inter-Continental Links to a Global System, 1990-2000", paper presented at 10th World Conference on Transport Research, Istanbul, Turkey.

34. Gelareh, S., Nickel, S. and Pisinger, D. (2010), "Liner shipping hub network design in a competitive environment", Transportation Research Part E, Vol. 46 No. 6, pp. 991-1004.

35. Holton, G. (2004), "Defining Risk", Financial Analysts Journal, Vol. 60 No. 6, pp. 19-25.

36. Hu, Y.H. and Zhu, D.L. (2009), "Empirical analysis of the worldwide maritime transportation network", Physica a-Statistical Mechanics and Its Applications, Vol. 388 No.10, pp. 2061-2071.

37. Hummels, D. and Schaur, G. (2013), "Trime as trade barrier", American Economic Review, Vol. 103 , pp. 2935-2959.

38. Imai, A., Shintani, K. and Papadimitriou, S. (2009), "Multi-port vs. hub-and-spoke calls by containerships", Transportation Research Part E, Vol. 45 No. 5, pp. 740-757.

39. Kaluza, P., Kolzsch, A., Gastner, M.T. and Blasius, B. (2010), "The complex network of global cargo ship movements", Journal of the Royal Society Interface, Vol. 7 No. 48, pp. 1093-1103.

40. Kivela, M., Areanas A., Barthelemy, M., Gleeson, J., Moreno, Y. and Porter, M. (2014), "Multilayer Networks", available at: http://arxiv.org/abs/1309.7233 (accessed 10 October 2015).

41. Lam, J.S.L. and Yap, W.Y. (2011), "Dynamics of liner shipping network and port connectivity in supply chain systems: analysis on East Asia", Journal of Transport Geography, Vol. 19 No. 6, pp. 1272-1281.

42. Lhomme, S. (2016), "Vulnerability and resilience of ports and maritime networks to cascading failures and targeted attacks", in Ducruet, C. (Ed.), Maritime networks: spatial structures and time dynamics, Routledge, New York, NY, pp. 229-241.

43. Lordan, O., Sallan, J.M., Simo, P. and Gonzalez-Prieto, D. (2014), "Robustness of the air transport network", Transportation Research Part E-Logistics and Transportation Review, Vol. 68, pp. 155163. 
44. Mangan, J., Lalwani, C. and Gardner, B. (2001), "Identifying relevant variables and modelling the choice process in freight transportation", International Journal of Maritime Economics, Vol. 3, pp. 278-297.

45. Mangan, J., Lalwani, C. and Fynes, B. (2008), "Port-centric logistics", International Journal of Logistics Management, Vol. 19 No. 1, pp. 29-41.

46. McCalla, R., Slack, B. and Comtois, P. (2005), "The Caribbean basin: Adjusting to global trends in containerization", Maritime Policy \& Management, No. 32, pp. 245-261.

47. Meng, Q. and Wang, S. (2011, "Liner shipping service network design with empty container repositioning", Transportation Research Part E-Logistics and Transportation Review, Vol. 47, pp. 695-708.

48. Moon, I.K., Qiu, Z.B. and Wang, J.H. (2015), "A combined tramp ship routing, fleet deployment, and network design problem", Maritime Policy \& Management, Vol. 42 No. 1, pp. 68-91.

49. Myers, M., Borghesi, A. and Russo, I. (2006), "Assessing the global environment", in Mentzer, J.T., Myers, M.B., Stank, T.P. (Eds.), Handbook of Global Supply Chain Management, SAGE Publications, Thousand Oaks, CA, pp. 39-49.

50. Notteboom, T. (2006), "The time factor in liner shipping services", Maritime Economics and Logistics, Vol. 8, pp. 19-39.

51. Notteboom, T. and Rodrigue, J.P. (2005), "Port regionalization: towards a new phase in port development", Maritime Policy and Management, Vol. 32 No. 3, pp. 297-313.

52. Pais, C., Freire, M. and Gonzalez, F. (2012), "General cargo and containership emergent routes: A complex networks description", Transport Policy, Vol. 24, pp. 126-140.

53. Panayides, P.M. and Song, D.W. (2008), "Evaluating the integration of seaport container terminals in supply chains", International Journal of Physical Distribution \& Logistics Management, Vol. 38 No. 7, pp. 562-584.

54. Panayides, P. and Song, D.W. (2013), "Maritime logistics as an emerging discipline", Maritime Policy \& Management, Vol. 40, pp. 295-308.

55. Sheffi, Y. (2005), The Resilient Enterprise, MIT Press, Boston.

56. Tang, O. and Musa, N. (2011), "Identifying risk issues and research advancements in supply chain risk management", Int. J. Production Economics, Vol. 133, pp. 25-34.

57. The Guardian, "Hanjin Shipping bankruptcy causes turmoil in global sea freight", $1^{\text {st }}$ September, 2016, available at: https://www.theguardian.com/business/2016/sep/02/hanjin-shippingbankruptcy-causes-turmoil-in-global-sea-freight (accessed 6 September 2016).

58. UNCTAD (2015), Review of Maritime Transport, UNCTAD, Geneva.

59. Wagner, S. and Neshat, N. (2010), "Assessing the vulnerability of supply chain using graph theory", International Journal of Production Economics, Vol. 126, pp. 121-129.

60. Wang, T. and Cullinane, K. (2006), "The efficiency of European container terminals and implications for supply chain management", Maritime Economics \& Logistics, Vol. 8, pp. 82-99.

61. Wang, J.E., Mo, H.H., Wang, F.H. and Jin, F.J. (2011), "Exploring the network structure and nodal centrality of China's air transport network: A complex network approach", Journal of Transport Geography, Vol. 19 No. 4, pp. 712-721. 
62. Watts, D.J. and Strogatz, S.H. (1998), "Collective dynamics of 'small-world' networks", Nature, Vol. 393 No. 6684, pp. 440-442.

63. Wilmsmeier, G., Hoffmann, J. and Sanchez, R. (2006), "The impact of port characteristics on international maritime transport costs", in Cullinane, K. and Talley, W. (Eds.), Port Economics, Research in Transportation Economics, Vol. 16, Elsevier, Amsterdam.

64. Windeck, V. (2012), A Liner Shipping Network Design, Berlin: Springer.

65. Woo, S.H., Pettit, S.J. and Beresford, A.K.C. (2013), "An assessment of the integration of seaports into supply chains using a structural equation model", Supply Chain Management: An International Journal, Vol. 18 No. 3, pp. 235-252.

66. Woolley-Meza, O., Thiemann, C., Grady, D., Lee, J.J., Seebens, H., Blasius, B., and Brockmann, D. (2011), "Complexity in human transportation networks: a comparative analysis of worldwide air transportation and global-cargo ship movements", The European Physical Journal, Vol. 84, pp. 589-600.

67. Xu, M., Zhenfu, L., Yanlei, S., Xiaoling, Z. and Shufei, J. (2015), "Evolution of regional inequality in the global shipping network", Journal of Transport Geography, Vol. 44, pp. 1-12.

${ }^{[1]}$ Argentina, Antigua and Barbuda, Bahamas, Belize, Brazil, Barbados, Canada, Chile, Colombia, Costa Rica, Dominica, Dominican Republic (DR), Ecuador, Grenada, Guatemala, Guyana, Haiti, Honduras, Jamaica, St. Kitts and Nevis, St. Lucia, St. Vincent and the Grenadines, Mexico, Nicaragua, Panama, Peru, El Salvador, Suriname, Trinidad and Tobago, Uruguay, United States (US), Venezuela. Bolivia and Paraguay were excluded from the sample because of being landlocked countries. 